\title{
Custeio-alvo como suporte às decisões em uma empresa de Publicidade e Propaganda
}

Samara Aparecida Dutra Filla
Graduação em Ciências Contábeis pela Universidade Estadual do Paraná - Campus de
Campo Mourão
Av. Comendador Norberto Marcondes, 733. Centro. Campo Mourão/PR. CEP: $87.302-$ 060

E-mail:samara_filla@hotmail.com

Juliane Andressa Pavão

Doutorado em andamento em Contabilidade pela Universidade Federal do Paraná UFPR Rua XV de Novembro, 1299. Centro. Curitiba/PR. CEP: 80.060-000 E-mail: julianepavao@hotmail.com

lasmini Magnes Turci Borges Mestrado em Ciências Contábeis pela Universidade Estadual de Maringá - UEM Autônoma Av. Colombo, 5790. Zona 7. Maringá/PR. CEP: 87.020-900 E-mail: iasminiborges@gmail.com

\section{RESUMO}

A pesquisa tem por objetivo aplicar o custeio-alvo como suporte às decisões na principal atividade de uma empresa de Publicidade e Propaganda. Como foco da pesquisa, elegeu-se a atividade de maior retorno da empresa, um pacote de serviços que inclui a gestão das redes sociais Facebook e Instagram, a criação e personalização de fanpages e anúncios patrocinados. Os procedimentos metodológicos consistem de uma pesquisa qualitativa e quantitativa, que foi realizada por meio de uma pesquisa diagnóstica, tendo a coleta de dados sido realizada por meio de observações, questionário e entrevistas semiestruturadas. O estudo apresentado auxilia o gestor que, por meio desta, pode ter maior facilidade para identificar os custos que influenciam o preço de venda de seus serviços, identificar as necessidades dos seus clientes, podendo alterar os serviços de acordo com a sua procura e, com essas informações, tomar a melhor decisão na prestação do serviço, alcançando o preço de mercado sem diminuir sua margem de lucro. Pode-se concluir que o custo real do pacote em estudo está abaixo do custo-meta, sem ser necessário realizar reduções no custo da empresa. As informações geradas por esta pesquisa auxiliam a tomada de decisão, principalmente a respeito da formação do preço de seus serviços, podendo servir de base para fechamento de futuros contratos e criação de novos pacotes.

Palavras-chave: Custeio-alvo. Gestão estratégica de Custos. Publicidade e propaganda. 
Custeio-alvo como suporte às decisões em uma empresa de Publicidade e Propaganda

Samara Aparecida Dutra Filla, Juliane Andressa Pavão, lasmini Magnes Turci Borges

Target costing as support for decisions in an Advertising company

\section{ABSTRACT}

The research aims to apply the target cost as a support for decisions in the main activity of an Advertising company. As a focus of the research, the company's highest return activity was selected, a package of services that included social network management Facebook and Instagram, creation and customization of fanpages, and sponsored ads. The methodological procedures consist of a qualitative and quantitative research, which was carried out by means of a diagnostic research, having the data collected through observations, questionnaire and semi-structured interviews. The present study assists the manager, who through the latter, can easily identify the costs that influence the sale price of his services, identify the needs of his clients and can change the services according to his demand, and with these information making the best decision in providing the service reaching the market price without decreasing its profit margin. It can be concluded that the actual cost of the study package is below the target cost, without having to make any reduction in the cost of the company. The information generated by this research helps decision making, specially regarding the formation of the price of its services, and can serve as the basis for closing future contracts, and creation of new packages.

Keywords: Target costing. Strategic Cost Management. Advertising.

\section{INTRODUÇÃO}

Em virtude da crise econômica e política, pode-se dizer que o campo mercadológico atual no Brasil se encontra altamente instável. Indicadores econômicos positivos apontaram que a recessão, iniciada em 2014, está sendo vencida, além de que economistas do mercado financeiro apontaram expectativas de alta para Produto Interno Bruto (PIB) já no fim de 2017 (Jornal Folha de São Paulo, 2017; Jornal Economia Estadão, 2017).

Esse cenário reflete, no campo mercadológico, que vender um produto ou serviço passou a ser cada dia mais difícil, pois o consumidor aproveita este período de competição entre as empresas para exigir cada vez mais, buscando produtos de qualidade e com preços baixos. O ambiente econômico criou a necessidade de uma reestruturação da gestão de custos (Hansen \& Mowen, 2001). Contudo, ter gestão de 
custos já não satisfaz totalmente as necessidades informacionais da empresa, visto que esta é voltada para o contexto interno (Bruni \& Famá, 2009). Devido a esse fato, os gestores passam a investir em uma gestão mais eficiente. As pressões competitivas mundiais, o crescimento do setor de serviços e os avanços nas tecnologias de informação e manufatura mudaram a natureza da economia que, por sua vez, deram início ao desenvolvimento de práticas inovadoras para a gestão de custos, dando espaço para a Gestão Estratégica de Custos (GEC).

Segundo Nakagawa (1991), a Gestão Estratégica de Custos (GEC) tem como característica uma posição considerada mais proativa, tendo seu foco voltado mais para o planeamento, gestão e também na redução de custos e, ainda, é mais compreensiva. Essa gestão vai além dos limites da empresa, pois não está voltada somente para o contexto interno, visto que também analisa o contexto externo, desde a origem de recursos materiais, humanos, financeiros e tecnológicos que utiliza até o consumidor final (Martins, 1998). A GEC, segundo Shank e Govindarajan (1997), pode ser considerada como uma análise de custos vista sob um panorama mais amplo, no qual elementos da estratégia se tornam mais conscientes, compreensíveis e formais. A ampliação da visão de Gestão de Custos para a visão de Gestão Estratégica de Custos é observada também por Souza e Clemente (2007) e Bacic (2008).

Entre os instrumentos da GEC, encontra-se o método Target Costing (TC), também conhecido como Custeio-Alvo, que vem sendo utilizado desde a década de 1970, com o objetivo de reduzir os custos e planejar estrategicamente os lucros (Sakurai, 1997). Ansari, Bell e Cypher (1997) definem o custeio-alvo como sendo "um sistema de planejamento de lucro e gerenciamento de custo" em que o foco está no preço e no cliente. A empresa estabelece o custeio-alvo estimando o preço de venda e subtraindo dele a margem de lucro desejada. O importante é projetar o produto ou serviço de modo que satisfaça os clientes e possa ser fabricado dentro de um custoalvo (Colauto \& Beuren, 2005).

Yazdifar e Askarany (2012) apontaram que grande parte dos estudos também assume que o TC é relevante apenas para as empresas de manufaturas e, portanto, 
acabam por não investigar a adoção dessa técnica nas empresas prestadoras de serviços, excluindo assim as empresas do setor de serviços das pesquisas e análises. Segundo os autores, o TC é igualmente utilizado entre empresas do setor de manufatura e de serviços.

Em um mercado concorrencial, não basta simplesmente adicionar a margem de lucro desejada aos seus custos para a fixação do preço. Nesse contexto, o custeio-alvo tem como objetivo usar o preço como parâmetro ao qual a empresa irá ajustar seus custos, de modo que obtém a margem e os resultados desejados pelo gestor. Pequenas e médias empresas usualmente não utilizam métodos de custeio adequados aos seus objetivos e planejamentos. Diante disso, tem-se a seguinte problematização da pesquisa: Como o custeio-alvo é aplicado em uma empresa prestadora de serviços de publicidade e propaganda para auxílio no gerenciamento de custos e preços?

O objetivo geral da pesquisa foi aplicar o custeio-alvo em uma empresa prestadora de serviços de publicidade e propaganda como auxílio ao processo decisório e delimita-se a uma agência de publicidade e propaganda do município de Campo Mourão, Estado do Paraná, no mês de junho de 2017, baseando-se na atividade de maior retorno da empresa, um pacote de serviços que inclui a gestão das redes sociais Facebook e Instagram, a criação e personalização de fanpages e anúncios patrocinados.

Partindo do pressuposto apresentado no estudo de Yazdifar e Askarany (2012), onde o TC está presente também nas empresas do setor de serviços e que existe um interesse crescente no uso de estratégias de redução de custos no estágio de planejamento dos produtos ou serviços, este estudo justifica-se pela importância de utilizar instrumentos da Gestão Estratégica de Custo a fim de auxiliar a tomada de decisões por meio da geração de informações. Esta pesquisa também contribui, trazendo informações de preços e custos ao gestor, visto que é um estudo aplicado a um caso específico: na modalidade de diagnóstico, com proposição de solução organizacional desta empresa de publicidade e propaganda. 
O estudo está estruturado em cinco sessões. Esta primeira apresenta a Introdução e objetivos que foram investigados. Na segunda sessão, discorre-se sobre a literatura do tema investigado, desde conceitos até estudos recentes. A terceira sessão apresenta a metodologia utilizada para a realização desta pesquisa. Na quarta sessão, são apresentados os cálculos e análises de custos e preços conforme o TC. Por fim, na quinta e última sessão, são evidenciados os principais achados da pesquisa.

\section{REFERENCIAL TEÓRICO}

Martins (1998) menciona que a GEC "requer análises que vão além dos limites da empresa para se conhecer toda a cadeia de valor: desde a origem dos recursos materiais, humanos, financeiros e tecnológicos que utiliza, até o consumidor final." Conforme Slavov (2013), com o objetivo de preencher as lacunas existentes pelo uso de sistemas tradicionais, surgem algumas práticas que, conforme o uso e objetivo de sua utilização pela empresa, podem ser caracterizadas como artefatos da GEC. Dentre elas, tem-se a análise do custo da qualidade, análise dos custos dos concorrentes, o sistema de custeio baseado em atividade e tempo (TDABC), o custeio-alvo, entre outras.

Este estudo tem como foco o Custeio-Alvo, que também é conhecido como custeio-meta, ou ainda, Target Costing. É um sistema desenvolvido no Japão que tem como base a engenharia de valor (Monden, 1999). Originalmente, foi criado pela Toyota, em 1965, estendendo-se pelas indústrias japonesas, especialmente a indústria automotiva, na década de 1970, logo após a crise do petróleo (Scarpin, 2000). Segundo Sakurai (1997), no Japão na década de 1970, quando a produção japonesa passou a ser diversificada, fabricando-se grande variedade de produtos com características distintas a fim de atender à demanda de consumidores mais exigentes, o custo-meta começou a ser aplicado visando reduzir o custo e planejar estrategicamente os lucros. 
Sakurai (1997) define custo-meta como sendo "[...] um processo estratégico de gerenciamento de custos para reduzir os custos totais, nos estágios de planejamento e de desenho do produto." Galindo (1998, p. 6) contribui, definindo custeio-alvo como "um ponto de encontro entre mercado e competências internas da empresa - entre valor e custo - e que inclui tanto ferramentas técnicas de apuração como métodos de gestão de custos"; analisa de forma ampla o contexto interno e externo, desde a produção do produto ou serviço até os clientes e concorrentes.

Para Monden (1999), o Custeio-Alvo tem como principais objetivos: [i] Otimizar o custo total do produto e, ao mesmo tempo, satisfazer as principais exigências do mercado, ou seja, qualidade e preço; [ii] Motivar os empregados a buscarem o lucro desejado, tornando o custo-alvo uma atividade de administração do lucro por toda a empresa. Diante dos princípios elencados, pode-se concluir que o custo do produto é definido a partir do preço de mercado. Pode-se visualizar na Figura 1 o processo do custeio-alvo.

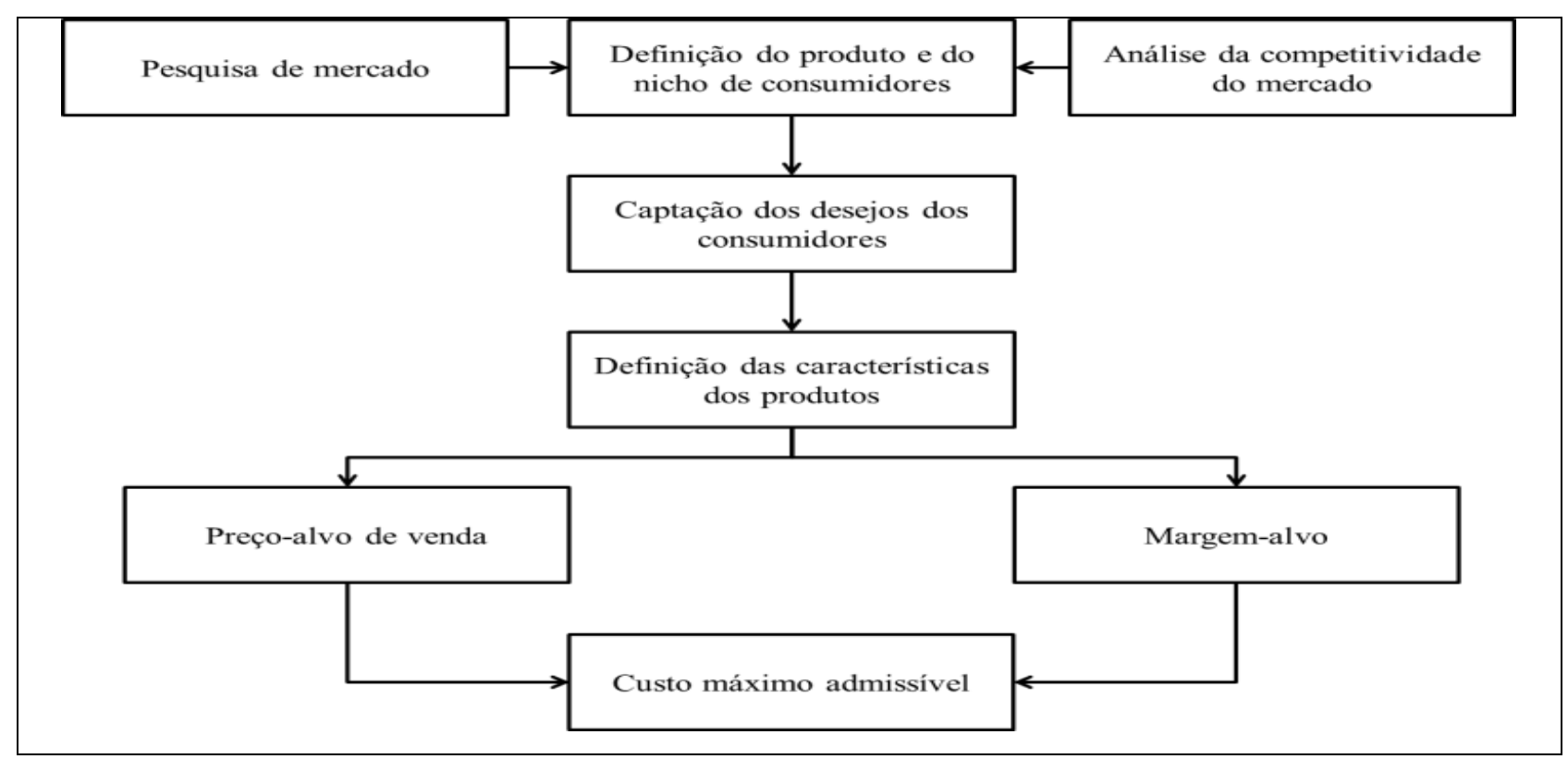

Figura 1. Etapas para o estabelecimento do custo máximo admissível

Fonte: Cruz e Rocha (2008), adaptado de Hansen (2002). 
O processo começa com uma pesquisa de mercado, a fim de identificar a necessidade e desejos dos clientes; isso dará informações para a definição do produto ou serviço e do nicho de consumidores. Após a definição do produto, é feito uma nova pesquisa com o intuito de captar os desejos dos consumidores em relação a esse produto, com o objetivo da plena adequação às necessidades dos clientes. Nesta etapa, ocorre a definição das características do produto. O próximo passo é estabelecer o preço de venda do produto, o valor que os clientes estão dispostos a pagar, ou seja, o preço de mercado. Em seguida, identificar a margem-alvo ou margem de lucro desejada pelo gestor, que pode ser calculada de acordo com a necessidade do gestor. Frente a isso, será possível estabelecer o custo máximo admissível, subtraindo do preço de venda a margem de lucro-alvo (Hansen, 2002).

Diversas são as pesquisas nacionais e internacionais que envolvem estudo, análise, aplicabilidade, viabilidade e utilidade do custeio-alvo nas entidades de diversos setores. Rotta (2005) analisou os conceitos e a aplicabilidade do custeio-alvo em empresas prestadoras de serviços de advocacia, em processos de concorrência pública. Verificou-se a clara relação da exigência do edital com os conceitos do custeioalvo, permitindo a aplicabilidade desse processo de gerenciamento de custos na decisão de como elaborar a proposta de prestação de serviços e concluiu que há várias restrições quanto à forma de determinação do custo do produto e, consequentemente, custo-alvo, e sugeriram a comparabilidade dos diversos métodos de custeio (pleno, absorção, variável e custeio baseado em atividades) no processo de custeio-alvo.

Camacho e Rocha (2006) investigaram a aplicação do custeio-alvo ao setor de prestação de serviços hospitalares e concluíram que o custeio-alvo é aplicável à indústria de serviços hospitalares, embora apresente maior grau de dificuldade para associar recursos e custos aos atributos comparativamente à indústria de manufatura.

Rodrigues (2008) pesquisou a adoção da Programação e Controle da Produção (PCP) dentro da teoria do custeio-alvo, como instrumento de gestão e controle de custos de novos produtos. Os achados evidenciam que sete empresas de grande porte do ramo têxtil do Vale do Itajaí (SC) adotam o PCP como ferramenta de gestão para 
estimar custo de novos produtos e a empresa entrevistada efetua pesquisas de mercado para conhecer o preço que o mercado deseja pagar, efetua o ajuste do custo máximo estimado na fase do projeto do produto de acordo com a teoria do custeio-alvo.

Biazebete, Borinelli e Camacho (2009) pesquisaram a possível aplicação, de forma integrada, dos conceitos do Custeio-Alvo e do Custeio Pleno numa indústria de confecções. Os autores concluíram que foi possível associar o custeio pleno à metodologia do custeio-alvo para a redução dos custos do produto ainda na fase de elaboração do modelo, garantindo a margem de lucro objetivada pela empresa.

Bertucci e Rocha (2010) investigaram se o Custeio-Alvo é utilizado pelo segmento de Autopeças no Brasil e, em caso positivo, se haveria alterações significativas em relação ao que a literatura preconiza e se fatores contingenciais exerceram influência em sua adoção. Concluíram que, embora se utilize um preço externo e os custos sejam ajustados até se atingir o custo máximo admissível, não foi possível afirmar que as empresas brasileiras de autopeças se utilizem de práticas que possam ser consideradas como Custeio-Alvo. As entrevistas realizadas indicaram que, caso o custo máximo admissível não pudesse ser atingido e ainda assim a empresa desejasse ganhar a cotação, ela poderá optar por sacrificar sua margem de lucro e simplesmente reduzir o preço apresentado na cotação.

Hamood, Omar e Sulaiman (2011) analisaram o conceito e aplicação do Target Costing (TC) em 10 países fora do contexto japonês, baseados em 35 publicações em inglês publicadas em várias revistas internacionais. Como análise geral, os autores encontraram uma variação significativa nos países pesquisados no que tange às práticas de TC, as etapas a serem seguidas e nos participantes envolvidos no processo de aplicação do TC. Os autores afirmam que fatores ambientais e questões relacionadas à melhoria de recursos do produto são cruciais para uma implementação bem sucedida do TC. Por fim, o artigo conclui afirmando um elemento de extrema importância no sucesso da implementação do TC; refere-se ao gerenciamento eficiente da cadeia de suprimentos, principalmente nas empresas de manufaturas. 
Wienhage, Rocha e Scarpin (2012) investigaram o impacto da aplicação da Target Costing e da Engenharia do Valor na precificação de um curso de pósgraduação lato sensu. A população do estudo foi composta por 298 alunos, sendo que obtiveram 165 respondentes válidos; os dados foram coletados no mês de novembro de 2009. Entre os achados, os autores constataram que, com a redução de alguns custos, foi possível adequar o preço do curso de acordo com as necessidades do mercado, corroborando assim a afirmação da literatura de que a aplicação da metodologia do Target Costing, aliada à Engenharia do Valor, são ferramentas adequadas à gestão de custos nas organizações.

Marques (2012) investigou as deduções e inferências que podem ser extraídas acerca da adoção, implementação e uso do Custeio-Alvo à luz da Teoria da Contingência e da Nova Sociologia Institucional. Concluiu, em relação à Teoria da Contingência, que o processo do Custeio-Alvo é aplicado em todos os projetos de desenvolvimento de produtos na empresa investigada. Em relação à Nova Sociologia Institucional, as análises indicaram que o mecanismo coercitivo foi o responsável pela adoção do Custeio-Alvo. Uma das conclusões foi que, nos casos em que a difusão se apresenta em alto grau da forma coercitiva, os mitos, as regras e as normas institucionais podem determinar a estrutura, mas não necessariamente as rotinas que dependem da interpretação que os atores fazem das mesmas, construindo as respostas de modo a acomodar as conveniências e interesses tanto do ambiente externo quanto do interno.

Yazdifar e Askarany (2012) questionaram em seu estudo a falta de pesquisas relacionadas ao TC nas empresas do setor de serviços. Os autores pesquisaram contadores gerenciais qualificados pela Chartered Institute of Management Accountants (CIMA) que trabalham em empresas de manufatura e serviços no Reino Unido, Austrália e Nova Zelândia sobre a adoção e implementação do TC. O estudo examinou a importância do TC para os tomadores de decisão quanto à adoção e implementação nos quesitos relacionados à vantagem relativa, compatibilidade, facilidade de utilização, demonstração de resultados e capacidade de avaliação. Os resultados da pesquisa 
indicaram que o TC é igualmente prevalente entre as empresas de manufatura e serviços, porém, no que tange aos níveis de implementação, existe uma diferença significativa entre as empresas desses dois setores. $O$ estudo mostrou que existe um interesse crescente no exame de todas as estratégias de redução de custos no estágio de planejamento e na adoção da engenharia de valor para incorporar ao produto os requisitos do cliente em vez de focar na adoção de estratégias de redução de custos no âmbito de produção.

Baharudin e Jusoh (2015) investigaram como o TC está sendo praticado e quais são os principais fatores que influenciam o Target Costing Management (TCM) em ambientes não japoneses, usando uma abordagem de estudo de caso. O estudo comparou as práticas de TC em um fabricante de automóveis da Malásia com os estudos de caso anteriores de fabricantes de automóveis japoneses e descobriu que o conceito fundamental de práticas de TC na empresa do caso era semelhante às práticas das empresas japonesas, porém houve algumas diferenças nos detalhes. As diferenças foram devidas à empresa do caso, que coordenou e reconfigurou seus recursos para se adaptarem às restrições contextuais, conforme destacado nas quatro proposições desenvolvidas.

No âmbito da prestação de serviços educacionais, De Souza et al. (2016) tiveram como objetivo em sua pesquisa determinar e identificar elementos que pudessem ser reduzidos/eliminados dos custos de uma Instituição de Educação Básica da cidade de Senhor do Bonfim, com o intuito de ocorrer assim a diminuição do valor da mensalidade, utilizando o método de custeio Target Costing. A população pesquisada foi composta pelos responsáveis financeiros dos alunos da Instituição analisada, no ano 2016, e obteve-se uma amostra de 128 respondentes. Os resultados da pesquisa apontaram que, mediante a redução de alguns atributos seria possível adequar o valor da mensalidade ao valor esperado pelo mercado. Os autores afirmam que, com a aplicação da Engenharia de Valor e do Custeio-Alvo, existe uma melhora da gestão nos custos das organizações, corroborando assim a afirmativa de que o TC é uma ótima ferramenta para a tomada de decisões. 
Okpala (2016) examinou o efeito da engenharia de valor no custo de produção, da manufatura enxuta na satisfação do cliente, do gerenciamento da cadeia de fornecimento na entrega eficiente de produto e também da filosofia kaizen melhoria contínua da qualidade do produto na indústria cervejeira na Nigéria. O pesquisador concluiu que a engenharia de valor, manufatura enxuta, gerenciamento da cadeia de suprimento e filosofia kaizen previram com segurança o custo de produção, a satisfação do cliente, a entrega eficiente do produto e a melhoria contínua, tendo todas as hipóteses não sido rejeitadas.

Silva (2016) teve como objetivo mapear nas 500 maiores empresas de Portugal sobre a utilização das técnicas de contabilidade gerencial, tendo como foco específico o Target Costing. Como achado, a autora teve a confirmação de que as empresas continuam não estando conscientes dos benefícios da utilização das técnicas de contabilidade gerencial na fase de desenvolvimento do produto/serviço. O estudo também apontou que as empresas portuguesas, em sua maioria, aplicam com uma maior frequência técnicas de contabilidade voltadas para gestão de custos e decisão estratégica, dando menos importância a técnicas direcionadas ao Planejamento, Controle e Performance. Por fim, foi verificado que diversas empresas apresentam uma utilização de técnicas semelhantes ao Target Costing, porém, não de forma consciente; várias empresas ainda afirmam utilizar o TC, porém, na prática, encontram-se utilizando técnicas adaptadas à sua realidade.

Gonçalves, Gaio e Silva (2018) investigaram as maiores empresas portuguesas e verificaram que a probabilidade de adoção do TC aumenta em resposta à inovação e diminui em resposta à incerteza que está relacionada ao ambiente econômico e tecnológico.

Como se pode observar por meio dos estudos pesquisados, o custeio-alvo é aplicável em diferentes ramos de atividade, inclusive na prestação de serviços, apesar da literatura existente enfocar predominantemente sua utilização em indústrias. 
Custeio-alvo como suporte às decisões em uma empresa de Publicidade e Propaganda

Samara Aparecida Dutra Filla, Juliane Andressa Pavão, lasmini Magnes Turci Borges

\section{PROCEDIMENTOS METODOLÓGICOS}

A pesquisa apresenta caráter qualitativo e quantitativo, uma vez que foram realizadas entrevistas semiestruturadas com o gestor da empresa objeto deste estudo e questionário aos clientes, a fim de conhecer a empresa, seus custos e as necessidades dos clientes.

Caracteriza-se também como uma pesquisa-diagnóstico. Segundo Martins e Theóphilo (2009), trata-se de uma "estratégia de investigação aplicada que se propõe explorar o ambiente, levantando e definindo problemas [...] podendo voltar-se para o ambiente externo", visto que foi realizada uma investigação específica na empresa para identificar o custo do pacote de serviço estudado, a aplicação do custeio-alvo e uma pesquisa de mercado nos quatro principais clientes com o objetivo de identificar as necessidades e o valor que estavam dispostos a pagar pelo serviço. A coleta de dados realizou-se por meio de observações, questionário e entrevistas semiestruturadas.

Inicialmente, foram realizadas pesquisas bibliográficas do assunto abordado em livros, artigos científicos, internet, entre outros, objetivando tornar possível verificar a correlação entre as bases teóricas e as aplicações práticas no caso. Em segundo momento, foram realizadas entrevistas semiestruturadas e aprofundadas com apenas uma única pessoa, o gestor e proprietário da empresa em estudo, já que se trata de uma empresa de pequeno porte que, além do proprietário, possui apenas um outro colaborador. Ainda nesta fase, foram realizadas visitas à empresa, com o intuito de conhecer e identificar os fatores influenciadores no custo do pacote de serviços estudado, por meio de observação direta e de análise de documentos administrativos relacionados (contas de água, internet, folha de pagamento entre outros). Portanto, foram realizadas triangulações das informações obtidas por meio das entrevistas e da observação direta na empresa, o que garante a validade dos dados analisados.

Em seguida, foram aplicados questionários aos quatro clientes fixos que adquiriram o pacote de serviços investigado, a fim de identificar suas necessidades e desejos, e qual valor monetário estes estavam dispostos a pagar pelo pacote de 
serviços. Um cliente optou por não responder o questionário; assim as análises foram realizadas com as três respostas obtidas. O questionário continha dez afirmativas em escala de 1 (pouco relevante) a 4 (muito relevante) sobre os atributos de serviços de publicidade e propaganda, além de duas questões abertas a fim de conhecer melhor a opinião dos clientes.

$\mathrm{Na}$ etapa seguinte, foram feitas as análises para identificação dos custos referentes ao pacote de serviço investigado. Com a resposta do questionário aplicado aos clientes, foi possível identificar os principais atributos do serviço prestado, dentro do pacote oferecido e para encontrar o valor monetário que estes estão dispostos a pagar. Ao encontrar o valor monetário que os clientes estavam dispostos a pagar pelo pacote de serviço em estudo, foi necessário identificar a margem de lucro que o gestor esperava obter para que fosse possível aplicar o custeio-alvo.

\section{APRESENTAÇÃO E ANÁLISE DOS RESULTADOS}

A empresa na qual se realizou o estudo foi constituída em 2012. Caracteriza-se como empresa de pequeno porte e é optante pelo regime tributário Simples Nacional. Tem como atividade a publicidade e propaganda. Possui apenas um funcionário e está localizada no município de Campo Mourão, Estado do Panará. Atua em diferentes áreas como, design gráfico, embalagens, identidade visual, campanhas, ações e planejamento de marketing, catálogos, websites e gestão de redes sociais. No entanto, para efeito deste estudo, considera-se apenas um dos serviços oferecidos pela empresa.

$\mathrm{Na}$ aplicação do custeio-alvo, não houve a necessidade de realização dos primeiros passos destacados na Figura 1, pois o serviço comercializado já existe dentro da empresa, e os clientes já estão definidos; portanto, só foi necessário identificar o custo máximo admissível. O serviço escolhido para estudo foi um pacote de gestão de redes sociais, devido a este ser um serviço fixo mensal e apresentar valor significativo 
em relação ao faturamento da empresa. Neste pacote estão inclusas a gestão das redes de Facebook e Instagram, a criação e personalização de fanpage e anúncios patrocinados. A empresa oferece 3 tipos de planos para seus clientes: o "Basic", o "Business" e o "Premium".

O plano Basic inclui planejamento, URL personalizada, 12 posts mensais, interação com fãs (comentários), capas sazonais e gestão de anúncios pagos; o valor deste pacote é $R \$ 1.250,00 /$ mês. O plano Business inclui planejamento, URL personalizada, 16 posts mensais, 1 post fim de semana, interação com fãs (comentários), capas sazonais e gestão de anúncios pagos. O valor deste pacote é $R \$$ $1.650,00$ /mês. E o plano Premium inclui planejamento, URL personalizada, identidade visual, 26 posts mensais, 2 posts fim de semana, interação com fãs (comentários), capas sazonais, campanhas promocionais e gestão de anúncios pagos (10\% do valor investido em anúncios). O valor deste pacote é $R \$ 2.250,00 /$ mês.

Com o objetivo de conhecer o ambiente empresarial, foram feitas entrevistas semiestruturadas com o gestor geral, o que possibilitou identificar os atributos e as características do serviço em estudo, identificar os clientes e verificar o custo. Ao questioná-lo a respeito de um método de custeio, foi constatado que não se utiliza nenhum método; portanto houve a necessidade e realizar o levantamento dos custos e de horas trabalhadas com o serviço investigado.

Por meio da ferramenta Excel, o gestor realizou o controle de horas trabalhadas por seu funcionário em cada empresa optante pelo pacote objeto de estudo. A Tabela 1 mostra quantas horas foram trabalhadas para cada cliente, somando um total de 21 horas e 8 minutos durante o mês de junho de 2017. 
Custeio-alvo como suporte às decisões em uma empresa de Publicidade e Propaganda

Samara Aparecida Dutra Filla, Juliane Andressa Pavão, lasmini Magnes Turci Borges

Tabela 1

Total de horas trabalhadas por cliente

\begin{tabular}{lcc}
\hline & Clientes & Horas $/$ mês \\
\hline A & & 7 horas \\
$B$ & & 4 horas e 30 minutos \\
C & 4 horas e 50 minutos \\
$D$ & 4 horas e 48 minutos \\
\hline & Total de horas & $\mathbf{2 1}$ horas e 8 minutos \\
\hline
\end{tabular}

Nota. Fonte: Elaborada pelas autoras com base nos dados da pesquisa.

Foram identificados todos os custos e despesas da empresa e feito um levantamento para encontrar o custo por hora, visto que esta foi a melhor maneira de atribuí-lo como custo do serviço estudado em relação ao mês de junho de 2017, como se pode verificar nas Tabelas 2, 3 e 4:

Tabela 2

Cálculo de folha de pagamento

\begin{tabular}{lc}
\hline Salário Base & $\mathrm{R} \$ 1.500,00$ \\
FGTS s/ salário & $\mathrm{R} \$ 120,00$ \\
Subtotal (deverá ser previsto no fluxo de caixa) & $\mathrm{R} \$ 1.620,00$ \\
Férias $1 / 12$ & $\mathrm{R} \$ 125,00$ \\
Adicional de $1 / 3$ férias & $\mathrm{R} \$ 41,67$ \\
FGTS férias e adicional de $1 / 3$ & $\mathrm{R} \$ 13,33$ \\
$13^{\circ}$ salário & $\mathrm{R} \$ 125,00$ \\
FGTS $13^{\circ}$ salário & $\mathrm{R} \$ 10,00$ \\
Subtotal (deverá ser provisionado pela empresa) & $\mathrm{R} \$ 315,00$ \\
\hline Custo efetivo total & $\mathbf{R} \$ \mathbf{1 . 9 3 5 , 0 0}$ \\
\hline
\end{tabular}

Nota. Fonte: Elaborada pelas autoras com base nos dados da pesquisa. 
Custeio-alvo como suporte às decisões em uma empresa de Publicidade e Propaganda

Samara Aparecida Dutra Filla, Juliane Andressa Pavão, lasmini Magnes Turci Borges

Tabela 3

Cálculo de Pró-labore

\begin{tabular}{ll}
\hline Pró-labore & $\mathrm{R} \$ 3.748,00$ \\
INSS s/ Pró-labore & $\mathrm{R} \$ 412,28$ \\
$\mathrm{IR}$ s/ Pró-labore & $\mathrm{R} \$ 145,56$ \\
\hline Custo efetivo total & $\mathbf{R} \$ \mathbf{4 . 3 0 5 , 8 4}$ \\
\hline
\end{tabular}

Nota. Fonte: Elaborada pelas autoras com base nos dados da pesquisa.

Tabela 4

Cálculo do custo efetivo por hora

\begin{tabular}{lcc}
\hline \multicolumn{1}{c}{ Custos } & Custo total mensal & Custo por hora \\
\hline Programas & $\mathrm{R} \$ 33,25$ & $\mathrm{R} \$ 0,15$ \\
Energia/aluguel/água & $\mathrm{R} \$ 450,00$ & $\mathrm{R} \$ 2,04$ \\
Internet/telefone & $\mathrm{R} \$ 165,00$ & $\mathrm{R} \$ 0,75$ \\
Depreciação do computador & $\mathrm{R} \$ 37,50$ & $\mathrm{R} \$ 0,17$ \\
Folha de pagamento & $\mathrm{R} \$ 1.935,00$ & $\mathrm{R} \$ 8,79$ \\
Pró-labore & $\mathrm{R} \$ 4.305,84$ & $\mathrm{R} \$ 19,57$ \\
Honorários Contábeis & $\mathrm{R} \$ 280,00$ & $\mathrm{R} \$ 1,27$ \\
\hline Total & $\mathbf{R} \mathbf{7 . 2 0 6 , 5 9}$ & $\mathbf{R} \mathbf{3 2 , 4 9}$ \\
\hline
\end{tabular}

Nota. Fonte: Elaborada pelas autoras com base nos dados da pesquisa.

As Tabelas 2 e 3 representam os cálculos relacionados à folha de pagamento $\mathrm{e}$ pró-labore, visto que a empresa possui apenas um funcionário e que este faz parte do custo juntamente com o pró-labore do gestor que também atua de forma direta na realização dos serviços prestados. Foi necessário identificar o valor total mensal de custo para o empresário, para então analisar o valor por hora, incluindo-o na Tabela 4.

De acordo com os valores dispostos na Tabela 4, o empresário tem um custo total mensal de $\mathrm{R} \$ 7.479,59$ para realizar todos os serviços prestados pela empresa. Para calcular os custos por hora, os valores com programas, energia, água, aluguel, internet, telefone, depreciação do computador, folha de pagamento, pró-labore e honorários contábeis foram divididos por 220 , que são as horas mensais trabalhadas; portanto o valor de $\mathrm{R} \$ 32,49$ corresponde ao custo efetivo geral por hora. No caso dos impostos, foi calculado cada pacote separadamente, devido à diferença de seus respectivos preços de venda. 
Tabela 5

Cálculo de imposto por pacote

\begin{tabular}{lcc}
\hline \multicolumn{1}{c}{ Pacote de serviço } & Preço de venda & Imposto mensal (6\%) \\
\hline Pacote Basic & $R \$ 1.250,00$ & $R \$ 75,00$ \\
Pacote Business & $R \$ 1.650,00$ & $R \$ 99,00$ \\
\hline
\end{tabular}

Nota. Fonte: Elaborada pelas autoras com base nos dados da pesquisa.

Em relação à sua atividade, a empresa em estudo está enquadrada no Anexo III das tabelas do simples nacional e na primeira faixa em relação ao faturamento dos últimos 12 meses; portanto, a alíquota a ser aplicada para cálculo do imposto é de 6\%, como disposto anteriormente na Tabela 5.

A fim de identificar as necessidades, desejos e o valor monetário que os clientes estão dispostos a pagar pelo pacote de serviços, foram aplicados questionários e, a partir deles, pode-se chegar aos resultados que serão apresentados a seguir. É importante ressaltar que o cliente B optou por não responder o questionário, portanto, todos os dados apresentados no decorrer da pesquisa, a partir de agora, referem-se às respostas de apenas três clientes denominados A, C e D. Na sequência, a Tabela 6 apresenta afirmativas questionadas aos clientes e o grau de importância por atributo do pacote de serviço por cada cliente, sendo 1 para pouco importante até 4 para muito importante. 
Custeio-alvo como suporte às decisões em uma empresa de Publicidade e Propaganda Samara Aparecida Dutra Filla, Juliane Andressa Pavão, lasmini Magnes Turci Borges

Tabela 6

Grau de importância por atributo do pacote de serviço

\begin{tabular}{lccc} 
& Cliente A & Cliente C & Cliente D \\
\hline Gestão de Facebook/fanpage, e instagram & Facebook & Facebook & Facebook \\
Desenvolvimento de cronograma para as publicações & 4 & 4 & 4 \\
Criação das campanhas de anúncios patrocinados & 2 & 2 & 4 \\
Gestão e relatórios de evolução de cada campanha & 4 & 4 & 4 \\
Relatórios mensais de engajamento, crescimento, curtidas etc & 4 & 3 & 3 \\
Criação de conteúdos diversificados, com artes, vídeos, gifs & 3 & 3 & 3 \\
Pesquisas sobre os produtos e serviços dos clientes; & 4 & 4 & 3 \\
Acompanhamento dos conteúdos da concorrência & 3 & 3 & 3 \\
Respostas a comentários e mensagens na fanpage & 4 & 4 & 4 \\
\hline
\end{tabular}

Nota. Fonte: Elaborado pelas autoras com base nos dados da pesquisa.

Como pode ser observado na Tabela 6, aplicaram-se graus de importância de 1 a 4, a fim de demonstrar quais atributos foram considerados necessários e de maior valor pelo cliente. A partir disso, o gestor poderá reduzir seus custos, se necessário, com base nos atributos menos desejados.

Questionou-se também o preço aceitável pelo cliente por um pacote que incluí os atributos que os mesmos elencaram como mais importantes e o preço aceitável por um pacote que inclui todos os atributos do pacote atual (sem especificações de quantidade de postagem por semana). O resultado pode ser observado na Tabela 7.

Tabela 7

Comparação entre preço aceitável e preço atualmente pago

\begin{tabular}{lcc}
\hline Cliente e Pacote & $\begin{array}{c}\text { Valor aceitável pelo pacote } \\
\text { completo }\end{array}$ & $\begin{array}{c}\text { Preço pago pelo pacote atual / Pacote } \\
\text { atual }\end{array}$ \\
\hline A Pacote Business & $\mathrm{R} \$ 1.500,00$ & $\mathrm{R} \$ 1.650,00$ \\
C Pacote Business & $\mathrm{R} \$ 1.500,00$ & $\mathrm{R} \$ 1.650,00$ \\
D Pacote Basic & $\mathrm{R} \$ 1.050,00$ & $\mathrm{R} \$ 1.250,00$ \\
\hline
\end{tabular}

Nota. Fonte: Elaborada pelas autoras com base nos dados da pesquisa.

É importante ressaltar que ao se aplicarem os questionários, não foi identificada a empresa objeto de estudo para que não influenciasse na resposta do cliente. Caso se soubesse que se tratava da empresa já contratada pelos mesmos, o resultado do 
questionário seria alterado com um valor desejável por eles, possivelmente mais abaixo do que o aceitável, com o intuito de, ao final do estudo, obter algum tipo de vantagem para a empresa.

Para definir o custo máximo admissível, é necessário identificar a margem de lucro desejável pelo gestor da empresa. Em entrevista com o mesmo, foi apresentado o desejo inicial da margem de lucro de $40 \%$. A partir disso, pode-se calcular o custo-alvo, no entanto, houve a necessidade de separar o custo-alvo por tipo de pacote, visto que os preços são diferentes. A Tabela 8 apresenta os custos máximos admissíveis de acordo com o custeio-alvo proposto para o pacote Basic adquirido pelo cliente $\mathrm{D}$ e o pacote Business adquirido pelo cliente $\mathrm{A}$ e $\mathrm{C}$.

Tabela 8

Custo-alvo

\begin{tabular}{lcc}
\cline { 2 - 3 } & Pacote Basic & Pacote Business \\
\hline Preço de mercado (cliente está disposto a & $\mathrm{R} \$ 1.050,00$ & $\mathrm{R} \$ 1.500,00$ \\
pagar) & $\mathrm{R} \$ 420,00$ & $\mathrm{R} \$ 600,00$ \\
$\begin{array}{l}\text { ( ) ) Margem de lucro (40\%) } \\
\text { ( =) Custo-alvo }\end{array}$ & $\mathrm{R} \$ 630,00$ & $\mathrm{R} \$ 900,00$ \\
\hline
\end{tabular}

Nota. Fonte: Elaborada pelas autoras com base nos dados da pesquisa.

Como disposto na Tabela 9, para encontrar-se o custo efetivo que o gestor teve com cada cliente, utilizou-se o custo efetivo por hora destacado na Tabela 4, multiplicou-se pelas horas trabalhadas com cada cliente durante o mês e, em seguida, somou-se com o valor dos impostos de cada pacote, visto que esse valor independe da quantidade de horas trabalhadas. 
Custeio-alvo como suporte às decisões em uma empresa de Publicidade e Propaganda

Samara Aparecida Dutra Filla, Juliane Andressa Pavão, lasmini Magnes Turci Borges

Tabela 9

Cálculo do custo efetivo por cliente

\begin{tabular}{lccc} 
& Cliente A & Cliente C & Cliente D \\
\cline { 2 - 4 } Custo efetivo/hora & $\mathrm{R} \$ 32,49$ & $\mathrm{R} \$ 32,49$ & $\mathrm{R} \$ 32,49$ \\
Horas trabalhadas no mês & $7: 00$ horas & $4: 50$ horas & $4: 48$ horas \\
(=) Custo efetivo & $\mathrm{R} \$ 227,43$ & $\mathrm{R} \$ 157,04$ & $\mathrm{R} \$ 155,95$ \\
(+) Impostos & $\mathrm{R} \$ 99,00$ & $\mathrm{R} \$ 99,00$ & $\mathrm{R} \$ 75,00$ \\
$(=)$ Custo efetivo total & $\mathrm{R} \$ 326,43$ & $\mathrm{R} \$ 256,04$ & $\mathrm{R} \$ 230,95$ \\
\hline
\end{tabular}

Nota. Fonte: Elaborado pelas autoras com base nos dados da pesquisa.

Tabela 10

Comparação do custo atual com custo-alvo por cliente

\begin{tabular}{lccc}
\hline Cliente & Custo efetivo total & $\begin{array}{c}\text { Custo-alvo (custo máximo } \\
\text { admissível) }\end{array}$ & Plano do pacote \\
\hline$A$ & $\mathrm{R} \$ 326,43$ & $\mathrm{R} \$ 900,00$ & Business \\
$\mathrm{C}$ & $\mathrm{R} \$ 256,04$ & $\mathrm{R} \$ 900,00$ & Business \\
$\mathrm{D}$ & $\mathrm{R} \$ 230,95$ & $\mathrm{R} \$ 630,00$ & Basic \\
\hline
\end{tabular}

Nota. Fonte: Elaborada pelas autoras com base nos dados da pesquisa.

A Tabela 10 mostra o custo real atual da empresa em comparação com o custoalvo. Notam-se os valores exatos em relação a cada pacote e que o custo real está bem abaixo do custo-alvo, o que evidencia a lucratividade da empresa nesses pacotes oferecidos.

Em uma nova entrevista com o gestor geral, foram apresentadas todas as informações obtidas por meio das pesquisas e todos os cálculos realizados a fim de que possa ser utilizado como suporte à tomada de decisão. Segundo o gestor, para uma empresa pequena que trabalha com prestação de serviços, uma das maiores dificuldades é identificar e calcular os custos reais dos seus serviços e saber o que realmente custa cada serviço e qual seu custo máximo admissível ou custo-alvo. Isso é de extrema importância, pois resolve um problema grande na empresa que é o trabalho com números aproximados. Sabendo-se desses valores reais, pode-se reduzir ou aumentar os preços sem medo de obter prejuízo. Esse é um grande passo para a lucratividade da empresa. 
O gestor ainda acrescenta que preza muito a informação contábil e que, quando se trabalha com um quadro reduzido, como é o caso da empresa, acaba fazendo de tudo um pouco e isso dificulta a parte administrativa e financeira da empresa; afirma que essas informações ajudarão muito a entender melhor o próprio negócio. As informações geradas com este estudo auxiliam o gestor em decisões a respeito de aumento ou diminuição dos preços dos pacotes, possíveis descontos para os clientes sem afetar a lucratividade, criação de novos pacotes com o objetivo de agregar novos consumidores.

\section{CONSIDERAÇÕES FINAIS}

O estudo teve como objetivo apresentar os efeitos da aplicação do custeio-alvo como suporte às decisões em uma empresa de Publicidade e Propaganda. A pesquisa teve como foco a atividade de maior retorno da empresa, um pacote de serviços que inclui a gestão das redes sociais Facebook e Instagram, a criação e personalização de fanpages e anúncios patrocinados.

Por meio de entrevistas ao gestor geral e clientes fixos do pacote estudado, foi possível identificar o custo, a margem de lucro desejada pelo gestor e o valor monetário de mercado, chegando aos cálculos para identificação do custo-meta. Pode-se constatar que o custo real do pacote é inferior ao custo-alvo.

Ao se finalizar a pesquisa, foram apresentadas ao gestor as informações valiosas geradas por meio do custeio-alvo que auxiliam na tomada de decisão, na resolução de problemas na formação do preço de venda de seus serviços, podendo servir de base para fechamento de futuros contratos e criação de novos pacotes. $O$ gestor afirma que possuir essas informações auxilia muito na lucratividade da empresa.

Vale salientar que o estudo limita-se a este caso específico; portanto os dados não podem ser generalizados, visto que empresas e atividades são diferentes umas das outras, independentemente de compartilhar do mesmo ramo de atividade. 
Com o intuito de melhorar as informações ao gestor da empresa, propõe-se analisar os outros meses, devido ao fato de as horas trabalhadas alterarem de um mês para outro, como também o estudo de outros serviços prestados. Propõe-se também a utilização de um programa para controle de horas trabalhadas durante todas as atividades da empresa, a fim de analisar se as outras atividades estão gerando lucro, assim como o pacote estudado.

\section{REFERÊNCIAS}

Ansari, S. L., Bell, J. E., \& Cypher, J. H. (1997). Target costing: the next frontier in strategic cost management. Irwin Professional Publishing.

Bacic, M. J. (2008). Gestão de Custos: uma abordagem sob o enfoque do processo competitivo e da estratégia empresarial. Curitiba: Juruá Editora.

Baharudin, N., \& Jusoh, R. (2015). Target Cost Management (TCM): a case study of an automotive company. Procedia-Social and Behavioral Sciences, 172 (1), 525-532.

Bertucci, C. E., Rocha, W. (2010). Custeio Alvo na indústria brasileira de autopeças. Congresso Brasileiro de Custos. Belo Horizonte, MG. Brasil, 17.

Biazebete, C. M., Borinelli, M. L., \& Camacho, R. R. (2009). Análise da aplicação do custeio-alvo e do custeio pleno em indústria de confecções: um estudo de caso. RCO - Revista de Contabilidade e Organizações - FEARP/USP, 3(5), 44-61 jan./abr.

Bruni, A. L., \& Famá, R. (2009). Gestão de Custos e Formação de Preços: com Aplicações na Calculadora Hp 12c e Excel. (5a ed.). São Paulo: Scipione.

Camacho, R. R., \& Rocha, W. (2006). Custeio-Alvo em Hospitais. ENANPAD Encontro da Associação Nacional de Pós-Graduação Pesquisa em Administração. Salvador, Bahia, Brasil, 30.

Colauto, R. D., \& Beuren, I. M. (2005). O Custeio-alvo como suporte às decisões para desenvolver novos produtos: um estudo em indústria moveleira. Revista Produção Online 5(1), 1-18. 
Cruz, C. V. O. A., \& Rocha, W. (2008). Custeio-alvo: reflexões sobre definições, finalidades e procedimentos. Revista Contemporânea de Contabilidade, 5(10), 3152.

De Souza, L. G., Santos, L. N., Coelho, D. C., Pereira, D. J., Bomfim, T. F. S., \& Santos, T. (2016). Target Costing: aplicação prática em uma instituição de educação básica na cidade de Senhor do Bonfim-Ba. Congresso Brasileiro de Custos - ABC. Porto de Galinhas, PE, Brasil, 23.

ECR Consultoria. A gestão estratégica de custos como diferencial competitivo nas empresas. Recuperado de: $<$ https://www.ecrconsultoria.com.br/biblioteca/artigos/controladoria-estrategica/agestao-estrategica-de-custos-como-diferencial-competi>. Acesso em: 29/out./ 2017.

Estadão Jornal Digital. Economia e Negócios. Mercado aumenta projeção para o PIB em $2017 \quad 2018 . \quad$ Recuperado de: $<$ http://economia.estadao.com.br/noticias/geral,mercado-aumenta-projecao-do-pibpara-2017-e-2018,70001985700 >. Acesso em: 29/out./2017.

Folha de S. Paulo. Economia brasileira tem alivio após três anos de crise. 2017. Recuperado de: http://www1.folha.uol.com.br/mercado/2017/08/1910891economia-brasileira-tem-momento-de-alivio-apos-tres-anos-de-crise.shtml>. Acesso em: 29/out./2017.

Galindo, M. L. (1998). El costo objetivo en la nueva gestión integral de custos. Gestion y Estrategia - Edición Internet - Universidad Autonoma Metropolitana, Cidade do México: Janeiro-Julho de 1998. p. 6.

Gonçalves, T., Gaio, C., \& Silva, M. (2018). Target costing and innovation -exploratory configurations: A comparison of fsQCA, multivariate regression, and variable cluster analysis. Journal of Business Research, 89, 378-384.

Hamood, H. H., Omar, N., \& Sulaiman, S. (2011). Target costing practices: a review of literature. Asia-Pacific Management Accounting Journal, 6(1), 25-46.

Hansen, J. E. (2002). Aplicação do custeio-alvo em cursos de pós-graduação lato sensu: um estudo sob o enfoque da gestão estratégica de custos. (Dissertação de Mestrado em Controladoria e Contabilidade). Faculdade de Economia, Administração e Contabilidade da Universidade de São Paulo - FEA/USP. São Paulo, SP, Brasil. 
Hansen, D. R., \& Mowen, M. M. (2001). Gestão de Custos: Contabilidade e Controle. São Paulo: Pioneira Thomson Learning.

Marques, K. C. M. (2012). Custeio alvo à luz da teoria da contingência e da nova sociologia institucional: estudo de caso sobre sua adoção, implementação e uso. (Tese de Doutorado em Contabilidade). Faculdade de Economia, Administração e Contabilidade, Universidade de São Paulo - FEA/USP. São Paulo, SP, Brasil.

Martins, G. de A., \& Theóphilo, C. R. (2009). Metodologia da investigação científica para ciências sociais aplicadas. (2a ed.). São Paulo: Atlas.

Mercados e Estratégias. Brasil: o cenário econômico atual. (2016). Recuperado de: http://www.mercadoseestrategias.com/news/brasil-o-cenario-economico-atual/>. Acesso em: 05/jun./2007.

Monden, Y. (1999). Sistema de redução de custos: custo-alvo e custo Kazen. Porto Alegre: Bookman.

Nakagawa, M. (1991). Gestão estratégica de custos: conceitos, sistemas e implementação. São Paulo: Atlas.

Okpala, K. E. (2016). Target costing implementation and competition: A case study of breweries industry. European Journal of Applied Business and Management, 2(2), 18-35.

Rodrigues, S. (2008). Estimação de custos de novos produtos por meio do custeio-alvo e da programação e controle da produção (pcp): área têxtil do vale do Itajaí, SC. (Dissertação de Mestrado em Contabilidade e Controladoria). Programa de PósGraduação, Universidade Regional de Blumenau - FURB. Blumenau, SC, Brasil.

Rotta, V. de C. (2005). A utilização do custeio-alvo em empresas prestadoras de serviços de advocacia em processos de concorrência pública. Congresso Brasileiro de Gestão Estratégica de Custos. Florianópolis, SC, Brasil, 9.

Sakurai, M. (1997). Gerenciamento integrado de custos. São Paulo: Atlas.

Scarpin, J. E. (2000). Target costing e sua utilização como mecanismo de formação de preço para novos produtos. (Dissertação de Mestrado em Contabilidade e Controladoria). Programa de Pós-Graduação. Universidade Norte do Paraná UNOPAR.

Shank, J. K., \& Govindarajan, V. (1997). A revolução dos custos: como reinventar e redefinir sua estratégia de custos para vencer em mercados crescentemente 
competitivos. (2a ed.). Rio de Janeiro: Campus.

Silva, M. L. D. (2016). Mapeamento de técnicas de controlo de gestão nas 500 maiores empresas Portuguesas: aplicação de Target Costing (Dissertação de Mestrado) Instituto Superior de Economia e Gestão. Universidade de Lisboa, Portugal.

Silveira, D. T., \& Córdova, F. P. (2009). A Pesquisa Científica. In: GERHARDT, T. E.; Silveira, D. T. (Orgs). Métodos de Pesquisa. Porto Alegre: Editora da UFRGS, p. 31-42.

Slavov, T. N. B. (2013). Gestão Estratégica de Custos: Uma contribuição para a construção de sua estrutura conceitual. (Tese de Doutorado em Contabilidade). Programa de Pós-Graduação em Contabilidade e Controladoria, Universidade de São Paulo - USP. São Paulo, SP, Brasil.

Souza, A., \& Clemente, A. (2007). Gestão de Custos: aplicações operacionais e estratégicas: exercícios resolvidos e propostos com utilização do Excel. São Paulo: Atlas.

Wienhage, P., \& Rocha, I., \& Scarpin, J. E. (jan.abr. 2012). Aplicação do Target Costing e Engenharia de Valor na Precificação de curso de Pós-Graduação. ABCustos Associação Brasileira de Custos, 7(1), 85-109.

Yazdifar, H., \& Askarany, D. (2012). A comparative study of the adoption and implementation of target costing in the UK, Australia and New Zealand. International Journal of Production Economics, 135(1), 382-392.

Data de Submissão: 06/02/2019

Data de Aceite: 29/07/2019 